\title{
Green Synthesis of Carvenone by Montmorillonite-Catalyzed Isomerization of 1,2-Limonene Oxide
}

\author{
Thao-Tran Thi Nguyen ${ }^{1}$, Duy-Khiem Nguyen Chau ${ }^{1}$, Fritz Duus ${ }^{2}$, Thach Ngoc Le ${ }^{1 *}$ \\ ${ }^{1}$ Department of Organic Chemistry, Hochiminh University of Science, Hochiminh City, Vietnam \\ ${ }^{2}$ Department of Science, Systems and Models, Roskilde University, Roskilde, Denmark \\ Email: *1enthach@hcm.vnn.vn
}

Received June 31, 2013; revised August 8, 2013; accepted August 25, 2013

Copyright (C) 2013 Thao-Tran Thi Nguyen et al. This is an open access article distributed under the Creative Commons Attribution License, which permits unrestricted use, distribution, and reproduction in any medium, provided the original work is properly cited.

\begin{abstract}
Montmorillonite was considered as a good heterogeneous catalyst for the isomerization of 1,2-limonene oxide into carvenone under solvent-free condition. Both conventional heating and green activations were tested in this research. The microwave-assisted isomerization afforded carvenone in high yield within only 6 minutes.
\end{abstract}

Keywords: Carvenone; Isomerization; Green Chemistry; Montmorillonite; Solvent-Free Synthesis

\section{Introduction}

Carvenone, $p$-menth-3-en-2-one, has been considered as a useful constituent for perfume, flavor, and fragrance $[1,2]$. This compound is one of the major products achieved in Brönsted acid-catalyzed isomerization of different precusors, e.g. dihydrocarvone [3,4] and 1,2-limonene oxide. Because the latter compound is easily prepared from naturally available limonene [5], the interest for direct syntheses of carvenone from 1,2-limonene oxide has been increasing [6-21]. However, most of the related reports showed that the selectivity towards carvenone was not good as expected. Arata's group developed a pathway in which 1,2-limonene oxide was isomerized over $\mathrm{H}_{2} \mathrm{SO}_{4} / \mathrm{SiO}_{2}$ or $\mathrm{SiO}_{2}-\mathrm{Al}_{2} \mathrm{O}_{3}$ to give carvenone in only modest yields [16]. Ravasio, et al. reported that a quantitative isomerization of limonene oxide can be carried out over copper supported on activated $\mathrm{SiO}_{2}-\mathrm{Al}_{2} \mathrm{O}_{3}$ in toluene, but this was not the selective route to prepare carvenone [21]. The most selective synthesis of carvenone directly from 1,2-limonene oxide was reported by Yoshito, et al. [2]. In this procedure, carvenone was prepared by dropwise addition of 1,2-limonene oxide into a tubular reactor filled with $\mathrm{CaA}$ zeolite at $200^{\circ} \mathrm{C}$ and 10 $\mathrm{mm} \mathrm{Hg}$ to give a mixture rich of carvenone.

Herein, we reported a mild and simple pathway to selectively obtain carvenone by the isomerization of 1,2-li-

${ }^{*}$ Corresponding author. monene oxide over montmorillonite prepared from Vietnamese natural clay. Various techniques including conventional heating $(\mathrm{CH})$, ultrasonic irradiation (US), and microwave irradiation (MW) were used to induce the reaction under solvent-free condition.

\section{Results and Discussion}

The isomerization of 1,2-limonene oxide 1 over Viet-namese montmorillonite under solvent-free conditions resulted in various products (Table $\mathbf{1}$ and Scheme 1) that were produced from the isomerization $(\underline{\mathbf{6}}, \underline{\mathbf{7}}, \underline{\mathbf{8}}, \underline{\mathbf{9}}, \underline{\mathbf{1 0}}, \underline{\mathbf{1 2}}$, and $\underline{\mathbf{1 3}})$, aromatization ( $\underline{\mathbf{3}})$, and other processes $(\underline{\mathbf{2}}, \underline{\mathbf{4}}$, and 5). Their presence as well as percentage in the final mixture depended on which technique was used. Table 1 summarized the influence of activation techniques on reaction outcomes. Besides being directly produced as one of the isomerization products from 1,2-limonene oxide, the formation of carvenone $\underline{\mathbf{1 2}}$ was also induced due to the shift of hydrogen in the framework of the other isomerization products. Therefore, it was not surprising that carvenone $\underline{\mathbf{1 2}}$ made up the largest proportions of the final mixtures, especially the samples obtained under the $\mathrm{CH}$ and MW techniques (Table 1). As a result, it was strongly believed that the isomerization of 1,2-limonene oxide into carvenone $\underline{\mathbf{1 2}}$ is an endothermic process. This again was confirmed through the results in Table 2 which showed the relationship between the temperature and the selectivity towards carvenone $\underline{\mathbf{1 2}}$ for the $\mathrm{CH}$ 
Table 1. The isomerization of 1,2-limonene oxide over Vietnamese montmorillonite ${ }^{\mathrm{a}}$.

\begin{tabular}{|c|c|c|c|}
\hline \multirow{2}{*}{ Compounds } & \multicolumn{3}{|c|}{ Selectivity (\%) } \\
\hline & $\mathrm{CH}^{\mathrm{b}}$ & $\mathrm{US}^{\mathrm{c}}$ & $\mathrm{MW}^{\mathrm{d}}$ \\
\hline$\alpha$-Fenchene (2) & - & - & 0.75 \\
\hline$p$-Cymene ( $\underline{\mathbf{3}})$ & 8.97 & - & 6.89 \\
\hline Limonene (י) & - & 3.64 & - \\
\hline trans-Linalool oxide (무) & 1.61 & 2.04 & 0.84 \\
\hline 1-Methoxy-4-(1'-methylethyl)cyclohexa-1,4-diene (ㅁ) & 3.27 & 12.09 & 0.81 \\
\hline trans-3-Caranone ( $\underline{7})$ & 0.99 & 1.27 & 1.65 \\
\hline cis-Dihydrocarvone ( $\underline{\mathbf{8}})$ & - & 19.69 & - \\
\hline trans-Dihydrocarvone $(\underline{\mathbf{9}})$ & - & 9.99 & - \\
\hline trans-Carveol (10) & - & 2.71 & - \\
\hline 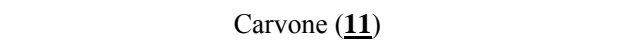 & - & - & 1.07 \\
\hline Carvenone ( $\underline{\mathbf{1 2}})$ & 85.16 & 47.70 & 88.00 \\
\hline 7,7-Dimethylbicyclo [3.3.0] octan-2-one (13) & - & 0.88 & - \\
\hline Yield of carvenone (\%) & 81 & 40 & 82 \\
\hline
\end{tabular}

a. 1,2 -limonene oxide:montmorillonite $=1: 0.08(\mathrm{w} / \mathrm{w}) ;$ b. $140^{\circ} \mathrm{C}, 60 \mathrm{~min}$; c. $111 \mu \mathrm{m}$ (amplitude), $75^{\circ} \mathrm{C}-77^{\circ} \mathrm{C}, 8 \mathrm{~min} ; \mathrm{d} .455 \mathrm{~W}\left(\right.$ power), $138^{\circ} \mathrm{C}-141^{\circ} \mathrm{C}, 6 \mathrm{~min}$.

Table 2. The influence of temperature on the reaction under $\mathrm{CH}^{\mathrm{a}}$.

\begin{tabular}{|c|c|c|c|c|c|}
\hline \multirow{2}{*}{ Compounds } & \multicolumn{5}{|c|}{ Selectivity (\%) } \\
\hline & $40^{\circ} \mathrm{C}$ & $60^{\circ} \mathrm{C}$ & $80^{\circ} \mathrm{C}$ & $100^{\circ} \mathrm{C}$ & $140^{\circ} \mathrm{C}$ \\
\hline$\underline{8}+\underline{9}$ & 47.32 & 44.77 & 44.06 & 30.24 & - \\
\hline$\underline{12}$ & 6.67 & 11.61 & 28.41 & 48.18 & 84.75 \\
\hline Others & 46.01 & 43.62 & 27.71 & 21.59 & 15.25 \\
\hline Yield of carvenone (\%) & 6 & 11 & 26 & 45 & 80 \\
\hline
\end{tabular}

a. 1,2-limonene oxide:montmorillonite $=1: 0.1(\mathrm{w} / \mathrm{w})$, reaction time: $60 \mathrm{~min}$.

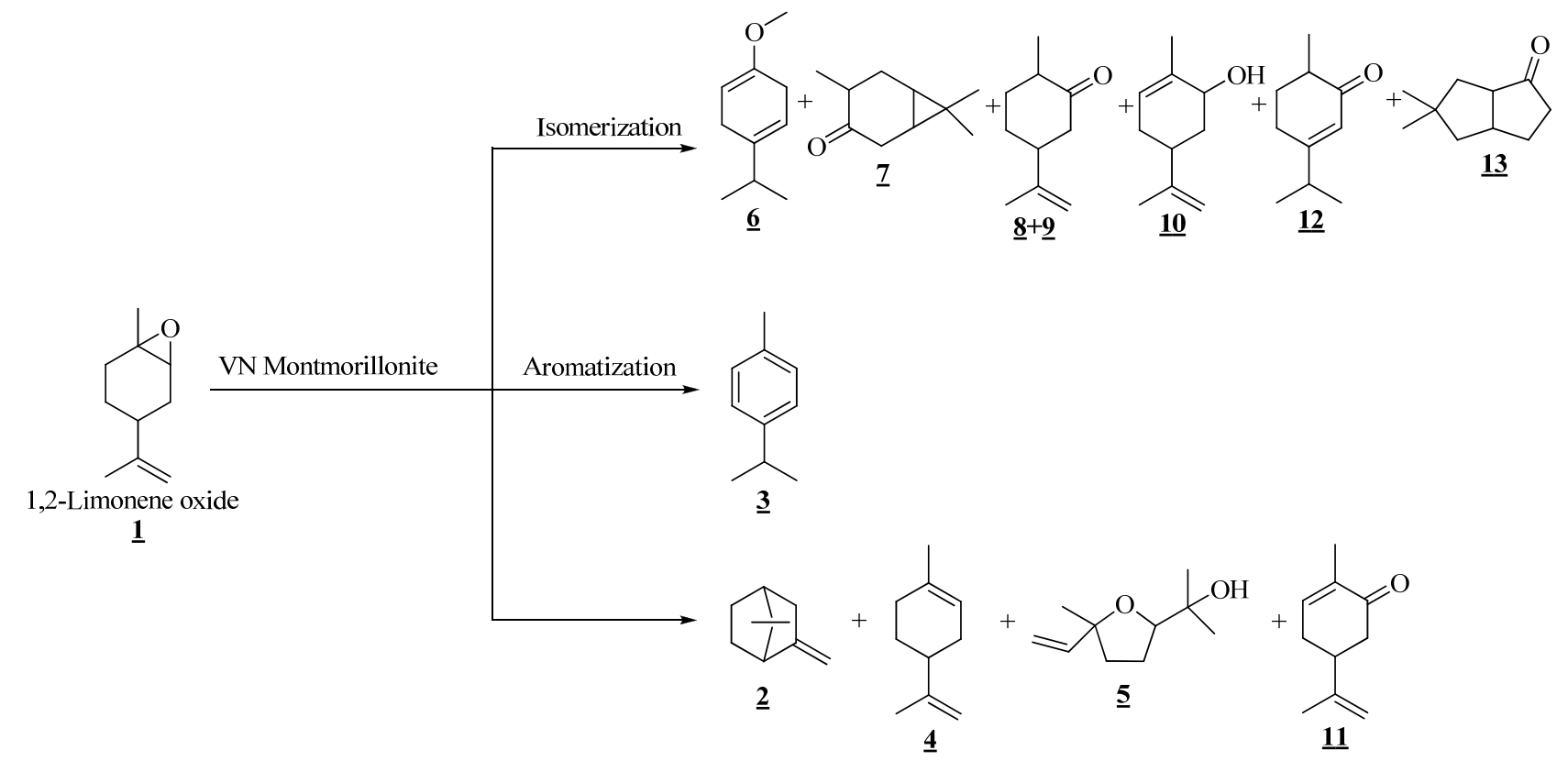

Scheme 1. Vietnamese montmorillonite-catalyzed isomerization of 1,2-limonene oxide. 
method. Obviously, there was a significant increase in the amount of the product carvenone $\underline{\mathbf{1 2}}$ from only $6.67 \%$ at $40^{\circ} \mathrm{C}$ to $85.16 \%$ at $140^{\circ} \mathrm{C}$.

The US method greatly enhanced the reactivity due to releasing the energy by cavitation collapsing the bubbles, especially for reactions involving solids. And as expected, the conversion of 1,2-limonene oxide could reach to the completion after a short irradiation time $(8 \mathrm{~min})$ at $75^{\circ} \mathrm{C}$ $77^{\circ} \mathrm{C}$ (Table 1). However, a poor selectivity towards carvenone 12 was detected because the ultrasound energy was not strong enough to shift hydrogen in the isomerization process.

Due to the effective absorbability for microwave energy of 1,2-limonene oxide and montmorillonite to supply heat for the total reaction mixture, the endothermic isomerization into carvenone $\underline{\mathbf{1 2}}$ was favored under the MW. A complete conversion was obtained after only 6 $\min$ at $138^{\circ} \mathrm{C}-141^{\circ} \mathrm{C}$ to afford carvenone $\underline{\mathbf{1 2}}$ in the nearly same yield compared with the $\mathrm{CH}$.

Unlike Yoshito's procedure [2], the isomerization of 1,2-limonene oxide using the modified montmorillonite as a Lewis acid catalyst can furnish carvenone $\mathbf{1 2}$ under solvent-free condition. Besides, good selectivity towards carvenone 12 could be obtained when using the $\mathrm{CH}$ and MW techniques. Consequently, the synthesis of carvenone can be accomplished in 6 minutes with $100 \%$ selectivity and $82 \%$ yield.

\section{Experimental}

\subsection{General}

All chemicals, unless otherwise noted, were purchased from commercial sources and used without further purification. The catalyst montmorillonite was prepared from Vietnamese natural clay according to Pesco method [23]. The analyses for quantification and identification were performed on GC-FID and GC-MS, respectively. GCFID analyses were recorded on Agilent 6890N GC, equipped with a fused silica capillary column DB-5 (30 $\mathrm{m} \times 0.32 \mathrm{~mm} \times 0.25 \mu \mathrm{m})$. GC-MS spectra were obtained with Agilent 7890A GC coupled to 5973C VL MSD Triple-Axis selective detector and equipped with a capillary column HP-5MS $(30 \mathrm{~m} \times 0.25 \mathrm{~mm} \times 0.25 \mu \mathrm{m})$.

\subsection{Preparation of 1,2-Limonene Oxide}

- Extraction of sweet orange peel oil: The fresh sweet orange peels were subjected to hydrodistillation for 6 $\mathrm{h}$. The resulting water-oil samples were extracted with diethyl ether. The combined ethereal extracts were dried over anhydrous sodium sulfate for $24 \mathrm{~h}$, filtrated, and rotary evaporated under vacuum to afford the essential oil as a colorless liquid.

- Isolation of limonene: Limonene was isolated from sweet orange peel oil by vacuum fractional distillation using Vigreux apparatus. The limonene fraction was collected at $55^{\circ} \mathrm{C}-56^{\circ} \mathrm{C}, 12 \mathrm{~mm} \mathrm{Hg}$ in the recovery yield of $83 \%$. The purity of limonene was checked by GC-MS analysis.

- Synthesis of 1,2-limonene oxide: The epoxidation of limonene was performed in the same way as previously reported by Mandelli and Silva (Scheme 1) $[5,22]$. The product was identified as a mixture of cis/trans-1,2-limonene oxide (69\%).

\subsection{General Procedure for Synthesis of Carvenone}

A $100 \mathrm{~mL}$ round-bottom flask was charged with 1,2limonene oxide $(1.0 \mathrm{~g})$ and montmorillonite $(0.08 \mathrm{~g})$. The reaction mixtures were then subjected to different techniques for organic synthesis:

- $\mathrm{CH}$ : The reaction flask was fitted with a condenser, immersed in an oil bath, heated and simultaneously stirred at $140^{\circ} \mathrm{C}$ for $60 \mathrm{~min}$.

- US: The reaction mixture was sonicated for $8 \mathrm{~min}$ at the amplitude corresponding to the wavelength of 111 $\mu \mathrm{m}$ emitted by a Cole Parmer GE130 Ultrasonic Processor equipped with a microtip and a probe fabricated from titanium alloy.

- MW: The reaction mixture was heated at the power of $455 \mathrm{~W}$ for $6 \mathrm{~min}$ in a modified domestic microwave oven KENWOOD SJW17.

Upon completion, the resulting mixtures were cooled to room temperature and diluted with diethyl ether. The solid catalyst was removed by filtration. The ethereal solutions were washed with water, dried over anhydrous sodium sulfate, and concentrated under reduced pressure to afford the mixture of products whose constituents were identified and quantified by GC-MS and GC-FID, respectively. The calculated yields of carvenone were 81, 40 , and $82 \%$ for the $\mathrm{CH}$, US, and MW techniques, respectively.

\section{Conclusion}

From the natural materials, such as clay and Citrus peel essential oil, carvenone can be efficiently prepared in high yield via the isomerization of 1,2-limonene oxide under solvent-free condition. Particularly, in the presence of microwave irradiation, the reaction can be greatly enhanced under mild conditions.

\section{Acknowledgements}

We would like to thank the Danish International Development Agency (DANIDA) for financial support via the Enhancement of Research Capacity (ENRECA) program and Nafosted (National Foundation for Science and 
Technology Development, Vietnam) through contract No. 104.01-2010.34.

\section{REFERENCES}

[1] J. Verghese, "Carvenone," Indian Perfumer, Vol. 24, No. 1, 1980, pp. 1-8.

[2] F. Yoshito, N. Masato and I. Kazunari, "Production of Carvenone,” Japanese Patent No. 62-114926, 1987.

[3] G. Büchi and R. E. Erickson, "Terpenes. II. The Reactions of Carvone and Dihydrocarvone with Methanol in the Presence of Sulfuric Acid," Journal of the American Chemical Society, Vol. 76, No. 13, 1954, pp. 3493-3495. doi:10.1021/ja01642a039

[4] E. E. Royals and L. L. Harrell, "Oxygenated Derivatives of d- $\alpha$-Pinene and d-Limonene. Preparation and Use of Monoperphthalic Acid," Journal of the American Chemical Society, Vol. 77, No. 12, 1955, pp. 3405-3408. doi:10.1021/ja01617a085

[5] D. Mandelli, M. C. A. Van Vliet, R. A. Sheldon and U. Schuchardt, "Alumina-Catalyzed Alkene Epoxidation with Hydrogen Peroxide," Applied Catalysis A: General, Vol. 219, No. 1-2, 2001, pp. 209-213. doi:10.1016/S0926-860X(01)00693-7

[6] H. Kropf and M. R. Yazdanbakhch, "Oxirane Durch Cooxidation Von Alkenen und Aldehyden Mit Sauerstoff," Synthesis, Vol. 10, 1977, pp. 711-713. doi:10.1055/s-1977-24546

[7] M. C. A. Van Vliet, D. Mandelli, I. W. C. E. Arends, U. Schuchardt and R. A. Sheldon, "Alumina: A Cheap, Active and Selective Catalyst for Epoxidations with (Aqueous) Hydrogen Peroxide," Green Chemistry, Vol. 3, No. 5, 2001, pp. 243-246. doi:10.1039/B103952K

[8] R. Buffon and U. Schuchardt, "Heterogenization of Alkene Epoxidation Catalysts," Journal of the Brazilian Chemistry Society, Vol. 14, No. 3, 2003, pp. 347-353. doi:10.1590/S0103-50532003000300002

[9] R. Saladino, A. Andreoni, V. Neri and C. Crestini, “A Novel and Efficient Catalytic Epoxidation of Olefins and Monoterpenes with Microencapsulated Lewis Base Adducts of Methyltrioxorhenium," Tetrahedron, Vol. 61, No. 5, 2005, pp. 1069-1075. doi:10.1016/j.tet.2004.11.065

[10] H. Ziyat, M. Y. A. Itto, M. A. Ali, A. Riahi, A. Karim and J.-C. Daran, "Convenient Synthesis of New Functionalized Cyclopropanes from Monoterpenic Olefins," Arkivoc, Vol. 12, No. 12, 2006, pp. 152-160. doi:10.3998/ark.5550190.0007.c18

[11] P. Buranaprasertsuk, Y. Tangsakol and W. Chavasiri, "Epoxidation of Alkenes Catalyzed by Cobalt (II) Calix[4]pyrrole," Catalysis Communications, Vol. 8, No. 3, 2007, pp. 310-314. doi:10.1016/j.catcom.2006.06.022

[12] N. Fdil, M. Y. A. Itto, M. A. Ali, A. Karim and J.-C.
Daran, "Epoxydation Aerobique des Terpens Naturels: Etude de l'Activité Catalytique des Nouveaux Comlexes Ru-1,2,4-triazepines," Tetrahedron Letters, Vol. 43, No. 48, 2002, pp. 8769-8771. doi:10.1016/S0040-4039(02)02072-5

[13] M. Aitali, M. Y. A. Itto, A. Hasnaoui, A. Riahi, A. Karim and J.-C. Daran, "A New Class of Triazepine-Ruthenium(II) Complexes: Synthesis, Crystal Structure and NMR Spectroscopic Properties," Journal of Organometallic Chemistry, Vol. 619, No. 1-2, 2001, pp. 265-270. doi:10.1016/S0022-328X(00)00680-X

[14] K. A. D. Swift, "Catalytic Transformations of the Major Terpene Feedstocks," Topics in Catalysis, Vol. 27, No. 1-4, 2004, pp. 143-155. doi:10.1023/B:TOCA.0000013549.60930.da

[15] I. C. Nigam and L. Levi, "Essential Oils and Their Constituents. XLII. Isomerization of Epoxides on Active Alumina," Canadian Journal of Chemistry, Vol. 46, No. 21, 1968, pp. 1944-1947. doi:10.1139/v68-565

[16] K. Arata, S. Akutagawa and K. Tanabe, "Isomerization of d-Limonene Oxide over Solid Acids and Bases," Journal of Catalysis, Vol. 41, No. 1, 1976, pp. 173-179. doi:10.1016/0021-9517(76)90213-X

[17] K. Arata and K. Tanabe, "Isomerization of d-Limonene Oxide over Aluminas," Chemistry Letters, Vol. 5, No. 4, 1976, pp. 321-322. doi:10.1246/cl.1976.321

[18] K. Arata, H. Takahashi and K. Tanabe, "Isomerization of d-Limonene Oxide Catalyzed by $\mathrm{NiSO}_{4}, \mathrm{FeSO}_{4}$ and $\mathrm{TiO}_{2}-\mathrm{ZrO}_{2}$," Roczniki Chemii (Polish Journal of Chemistry), Vol. 50, No. 12, 1976, pp. 2101-2106.

[19] T. Kurata, H. Takao, N. Kawashima and M. Hiroshi, "Isomerization of $d$-Limonene-1,2-Epoxide with Activated Carbon Catalyst," Yukagaku, Vol. 34, No. 12, 1985, pp. 1032-1304.

[20] B. M. Choudary and Y. Sudha, " $\mathrm{Fe}^{3+}-$ Montmorillonite: An Efficient Heterogeneous Catalyst for Highly Regioselective Alcoholysis of Epoxides," Synthetic Communications, Vol. 26, No. 16, 1996, pp. 2989-2992. doi:10.1080/00397919608004602

[21] N. Ravasio, F. Zaccheria, M. Guidotti and R. Psaro, "Mono- and Bifunctional Heterogeneous Catalytic Transformation of Terpens and Terpenoids," Topics in Catalysis, Vol. 27, No. 1-4, 2004, pp. 157-168. doi:10.1023/B:TOCA.0000013550.28170.6a

[22] J. M. S. Silva, F. S. Vinhado, D. Mandelli, U. Schuchardt and R. Rinaldi, "The Chemical Reactivity of Some Terpenes Investigated by Alumina Catalyzed Epoxidation with Hydrogen Peroxide and by DFT Calculations," Journal of Molecular Catalysis A: Chemical, Vol. 252, No. 1-2, 2006, pp. 186-193. doi:10.1016/j.molcata.2006.02.042

[23] T. W. Del Pesco, "Modified Montmorillonite Clay Catalyst,” US Patent, No. 4235751, 1980. 